\title{
Surgical Outcome Following Hip Fracture in Patients > 100 Years Old: Will They Ever Walk Again?
}

\author{
Sachin Patil ${ }^{1}$, Bertrand Parcells ${ }^{2}$, Alexis Balsted ${ }^{3}$, Ronald S. Chamberlain ${ }^{1,3,4}$ \\ ${ }^{1}$ Department of Surgery, Saint Barnabas Medical Center, Livingston, USA \\ ${ }^{2}$ Northeastern Universities College of Medicine, Rootstown, USA \\ ${ }^{3}$ Saint George’s University School of Medicine, Grenada, West Indies \\ ${ }^{4}$ Department of Surgery, University of Medicine and Dentistry of New Jersey, Newark, USA \\ Email: rchamberlain@sbchs.com
}

Received August 29, 2012; revised September 30, 2012; accepted October 8, 2012

\begin{abstract}
Introduction: Advances in medicine have led to a growth in the centenarian population ( $>100$ years old). Centenarians are a largely unstudied population but as longevity increases, so will the cost of providing care for this group. Methods: One hundred and ten patients were admitted to SBMC 195 times between 2000 and 2009. Thirteen patients were treated for hip fracture. Data abstracted from the charts of these patients including age, gender, ethnicity, co-morbidities, advance directives (ADRs), functional status, length of stay (LOS), pre-operative and post-operative residential status and ambulatory status, ASA grade, type of anesthesia, duration of surgery and for complications of surgery or anesthesia. Results: The mean age was 101.2 years (100 to 104 years) with an M:F ratio of 2:11. The most common co-morbidities were hypertension, anemia, congestive heart failure (CHF) and coronary artery disease. Among the 13 patients with hip fractures, 12 had operative intervention while one was treated conservatively. The mean ASA grade was $2.75(1-4)$. Five patients had surgery under general anesthesia and seven received spinal anesthesia. Five patients received a bi-polar hip replacement and seven patients underwent internal fixation. The mean operative time was 47.6 min (27 - 90 $\mathrm{min})$. Five $(41.7 \%)$ patients required a peri-operative blood transfusion. The mean post-anesthesia recovery score was $9.42(9$ - 10). All patients, except two, were returned to their pre-operative ambulatory status. Advanced directives were held by only $30.8 \%$ of patients on admission. There were 2 post-operative morbidities and 1 mortality. Conclusions: Centenarians represent a high-risk-surgical population due to their age and associated comorbidities. Hip fracture is the cause of $>10 \%$ of all admissions and accounts for $29 \%$ of all surgical procedures in this age group. Despite their age and comorbidities, surgery for hip fracture is well tolerated and nearly all patients were returned to their pre-hospital ambulatory status. Education on advanced directives is lacking.
\end{abstract}

Keywords: Hip Fracture; Centenarians

\section{Introduction}

Advances in medical diagnosis and treatment have fostered the growth of a previously static population, the centenarians. The number of Americans living to 100 years has increased ten fold since 1970 and is expected to reach 1 million by 2050 [1]. Centenarians are a largely unstudied group due to their small numbers, however as longevity increases, so does the need to improve our understanding of the medical and surgical requirements of this population.

Hip fracture is one of the most common causes of morbidity in adults 65 years of age and older. The number of fractures is expected to rise with the growing elder population and will likely exceed 500,000 per year by 2040 [2]. People older than 85 years are 10 to 15 times more likely to sustain hip fractures than people between
60 to 65 years [3]. This injury often results from minor trauma and is associated with severe morbidity, reduced quality of life and premature death [4]. Greater than $90 \%$ of hip fractures in this age group occur from a fall from a standing height [5-7], despite its peak incidence in the oldest patients, there are very few reports on hip fracture outcomes in centenarians [8-10]. The aim of this report is to review hip fracture outcomes among centenarians treated at a tertiary care community hospital. Patient outcomes evaluated included return to ambulatory status, need for blood transfusion, and postoperative morbidity, mortality and living status.

\section{Methods}

A retrospective review of all patients with hip fracture admitted to the Saint Barnabas Medical Center (SBMC) 
in Livingston, New Jersey over a 10-year period (between 2000 and 2009) was performed. Pertinent data was collected using a standard data collection sheet after approval from the institutional review board (IRB\# 09-22). A total of 195 hospital admissions corresponding to 110 unique patients over 100 years old were identified. Among this group 13 patients were admitted with a diagnosis hip fracture. Age, gender, ethnicity, comorbidities, advance directives (ADRs), functional status and LOS were abstracted. The data was analyzed for differences in preoperative and postoperative residential status, ambulatory status, ASA score, as well as type of anesthetic, duration of surgery and complications related to surgery or anesthesia. For statistical calculations SPSS ${ }^{\odot}$ 18.0 Windows software was used, Chi-square test was used to compare categorical values and student's $t$ test was used to compare quantitative values and statistical significance was set at $p<0.05$.

\section{Results}

The demographic and clinical characterestics of the patients are represented in Table 1.

\subsection{Age and Sex}

The mean age of the patients was 101.2 years (100 to 104 years). The mean age among male and female patients was 100 years and 101.3 years (range: 100 to 104 years), respectively. The M:F ratio was 2:11.

\subsection{Peri-Operative Living Status}

Forty six percent (six of 13) of patients were living in their home with relatives or hired help prior to hip fracture. Three (25\%) patients were admitted from an assisted living home and two (16.7\%) patients each were living in a nursing home or rehabilitation center. Postoperatively $46.2 \%$ patients were discharged to a nursing home, $38.5 \%$ patients were discharged to a rehabilitation center, one patient died $(7.7 \%)$ and the living status of one patient (7.7\%) was unknown.

\subsection{Peri-Operative Activities of daily living and Ambulatory status}

Pre-operatively, 69\% ( $\mathrm{N}=9$ ) of the patients required assistance with $>3$ activities of daily living. Sixty one percent of patients $(\mathrm{N}=8$ ) required a walking device (cane/walker) for ambulation, three patients (23\%) required constant supervision during ambulation, and the ambulatory status of one patient $(7.7 \%)$ is unknown. Ten patients (77\%) returned to their preoperative ambulatory status. Among the three patients who did not return to their preoperative ambulatory status, two patients (15.4\%) developed decubitus ulcer and one patient (8.3\%) died.
The extent to which these patients postoperatively returned to independent activities of daily living could not be assessed.

\subsection{Comorbidities}

The average number of comorbidities per patient was 3.8 (range: 1 - 7) per patient. The average number of comorbidities for males was 4.5 (range: 3 - 6), while the average number of comorbidities for females was 3.7 (range: 1 - 7). The most common co-morbidities were hypertension $(\mathrm{N}=6,46.1 \%)$, anemia $(\mathrm{N}=5,38.5 \%)$, congestive heart failure $(\mathrm{N}=4,30.8 \%)$, atrial fibrillation $(\mathrm{N}=4$, $30.8 \%)$, coronary artery disease $(\mathrm{N}=4,30.8 \%)$ and malnutrition $(\mathrm{N}=4,30.8 \%)$.

\subsection{Mode of Injury and Type of Fracture}

All but one hip fracture occurred after minor injury, such as fall from a standing height. One patient developed hip pain while transferring from bed to chair, and was found to have an undisplaced intertrochanteric fracture. Overall, seven (53.8\%) patients had intertrochanteric fractures (6 females, 1 male) and six (46.2\%) patients had femoral neck fractures (5 females, 1 male).

\subsection{Anesthesia}

The mean American Society of Anesthesiologists (ASA) score was 2.75 (range: 1 - 4). The mean ASA score for male patients was 3 and it was 2.7 (range: 1 - 4) for females. One patient (7.7\%) had an ASA score of 1 , two patients (15.4\%) had an ASA score of 2 and nine patients (69.2\%) had an ASA score of 3 - 4. General anesthesia was used for five patients ( 2 males, 3 females) while seven patients received spinal anesthesia (7 females). The mean post-anesthesia recovery scores were 8.4 (range: 4 - 10) and 9.42 (range: 9 -1 0) at admission and discharge from the post-anesthesia care unit (PACU).

\subsection{Surgery}

Among the thirteen patients with hip fractures, 12 (92.3\%) underwent operative intervention and one patient (7.7\%) was managed conservatively. Five (38.5\%) patients underwent a bi-polar hip replacement and seven (53.8\%) patients underwent internal fixation. Five (38.5\%) patients required a blood transfusion. The mean operative time was $47.58 \mathrm{~min}$ (27 $\mathrm{min}$ - $90 \mathrm{~min}$ ). The sole patient (7.7\%) managed conservatively had an undisplaced intertrochanteric fracture.

\subsection{Morbidity and Mortality}

Two (15.3\%) patients developed a sacral decubitus ulcer in the postoperative period and one (7.7\%) patient de- 
Table 1 Demographic and clinical characteristics of centenarians undergoing hip surgery (200-2009).

\begin{tabular}{|c|c|c|c|}
\hline Demographic and clinical features & Male & Female & Overall \\
\hline Total patients & 2 & 11 & 13 \\
\hline Mean age, years (range) & 100 & $101.3(100-1004)$ & $101.2(100-104)$ \\
\hline Mean height, ft (range) & $5.5(5.1-5.7)$ & $5.3(4.8-5.7)$ & $5.4(4.8-5.8)$ \\
\hline Mean weight, lbs (range) & $141.2(111.5-170)$ & $111.1(85-160)$ & $131.8(85-170)$ \\
\hline \multicolumn{4}{|l|}{ Residential status } \\
\hline Home with relatives or hired help & 0 & 6 & $6(46.2 \%)$ \\
\hline Assisted living & 1 & 2 & $3(23 \%)$ \\
\hline Nursing home & 0 & 2 & $2(15.4 \%)$ \\
\hline Rehabilitation & 1 & 1 & $2(15.4 \%)$ \\
\hline \multicolumn{4}{|l|}{ ADL dependency } \\
\hline 0 & 0 & 0 & 0 \\
\hline $1-3$ & 0 & 2 & $2(15.4 \%)$ \\
\hline$>3$ & 2 & 7 & $9(69.3 \%)$ \\
\hline Unknown & 0 & 1 & $1(7.7 \%)$ \\
\hline \multicolumn{4}{|l|}{ Pre-operative mobility } \\
\hline Independently mobile & 0 & 0 & 0 \\
\hline Mobile with aids & 1 & 7 & 8 (61.5\%) \\
\hline Mobile with assistance & 1 & 2 & $3(23 \%)$ \\
\hline Unknown & 0 & 1 & $1(7.7 \%)$ \\
\hline Co-morbidities (range) & & & $3(0-7)$ \\
\hline $0-3$ & 2 & 7 & $9(69.3 \%)$ \\
\hline$>3$ & 0 & 4 & $4(30.8 \%)$ \\
\hline \multicolumn{4}{|l|}{ Advanced directives } \\
\hline Available & 1 & 3 & $4(30.8 \%)$ \\
\hline Not-available & 1 & 7 & 8 (61.5\%) \\
\hline Unknown & 0 & 1 & $1(7.7 \%)$ \\
\hline \multicolumn{4}{|l|}{ ASA grade } \\
\hline I & 0 & 1 & $1(8.3 \%)$ \\
\hline II & 0 & 2 & $2(16.7 \%)$ \\
\hline III & 2 & 6 & $8(66.7 \%)$ \\
\hline IV & 0 & 1 & $1(8.3 \%)$ \\
\hline \multicolumn{4}{|l|}{ Anesthesia type } \\
\hline GA & 2 & 3 & $5(41.7 \%)$ \\
\hline Spinal & 0 & 7 & $7(58.3 \%)$ \\
\hline Mean length of surgical procedure, min (range) & $29.5(27-32)$ & $51.2(29-90)$ & $47.58(27-90)$ \\
\hline \multicolumn{4}{|l|}{ Mean post-anesthesia recovery score } \\
\hline at admission to PACU (range) & $9(8-10)$ & $8(4-10)$ & $8.4(4-10)$ \\
\hline at discharge from PACU (range) & $9.5(9-10)$ & $9.4(9-10)$ & $9.42(9-10)$ \\
\hline Mean length of stay, days (range) & $10.5(7-14)$ & $13.5(6-28)$ & $13(7-28)$ \\
\hline Morbidity & 0 & 2 & $2(16.7 \%)$ \\
\hline Mortality & 0 & 1 & $1(8.3 \%)$ \\
\hline Change in mobile status at the time of discharge & & & $2(15.4 \%)$ \\
\hline Mobile with aids to wheel chair/bed bound & 0 & 2 & $2(15.4 \%)$ \\
\hline
\end{tabular}

Abbreviations: ft: feet, lbs: pounds, ADL: activities of daily living, GA: general anesthesia, min: minutes, PACU: post-anesthesia care unit. 
veloped pneumonia, which progressed to multisystem failure and death.

\subsection{Advanced Directives}

Only four (30.8\%) patients had written advanced directives at admission. The advanced directives were held by one male and three female patients. Information regarding the status of advanced directives in one female patient was not available. Two (15.3\%) patients signed new advanced directive during hospitalization.

\section{Discussion}

It is generally accepted that surgery for hip fractures is mandatory especially in the elderly, since extended immobilization leads to higher rates of morbidity $[11,12]$. Hornby et al. reported on 55 surgically and 51 conservatively managed hip fractures in elderly patients (age $>60$ years). In the conservative group, 8 (16\%) patients developed pin tract infection, 20 (39\%) patients developed pin loosening, and $5(10 \%)$ patients developed traction sores. There was no significnt difference in the in-hospital mortality between the surgically treated $(\mathrm{N}=$ $13,24 \%)$ and conservatively managed $(\mathrm{N}=11,22 \%)$ patients, $p=0.5$. At 6-months follow-up 16 (31.3\%) patients in the conservative group had lost independence compared to $9(16.4 \%)$ patients in the surgical group, $p<$ 0.001 [13]. When deciding on best treatment for centenarians with hip fractures little is known about whether these patients will benefit from surgical intervention. Low published rates of restoration to pre-operative living and ambulatory status among patients of advanced age following hip surgery raise doubts as to whether hip surgery is cost effective and will add quality adjusted life year to the centenarian population. Given the high rate of reported disability and mortality among the oldest population, it is imperative that the cost and benefit of any surgical intervention be critically analyzed.

Forster et al. reported in-hospital, 1-month and 6month post-operative mortality rates of $31 \%, 31 \%$ and $50 \%$, respectively, among 13 centenarians treated surgically for hip fractures [8]. Oliver et al. reported in-hospital, 1-month and 4-month mortality rates of $11.1 \%$, $33.3 \%$ and $50 \%$, respectively in a similar cohort of 18 patients [9]. Finally, Krishnan et al. reported an in-hospital mortality rate of $3.2 \%$ among centenarians undergoing hip arthroplasty for fracture and osteoarthritis [14]. In the current study the in-hospital mortality rate was 7.7\% which is lower than prior reports in centenarians and consistent with van de Kerkhove et al who reported a mortality rate of $11.6 \%$ (18 of 155 patients) in nonagenarians undergoing hip surgery [15]. Nearly all studies have concluded that mortality risk increases with increasing number of comorbidities, which are common among patients over 100 years of age. In patients between 66 to 75 years of age, Kenzora et al reported that the presence of four or more medical comorbidities significantly increased the postoperative mortality rate following surgery for hip fractures [16]. Similarly, in patients 95 years of age with hip fractures, Holt et al. reported a relative risk of mortality of $0.36,1.33$ and 2.33 for patients with no comorbidities, one or two comorbidities, and three or four comorbidities, respectively [11]. In the current report the sole patient who died had three comorbidities and succumbed to multisystem failure following aspiration pneumonia.

Postoperative restoration to baseline living and postoperative ambulatory status are significant factors associated with quality of life and are of major concern in the aged population. Minor changes in daily functions often lead to significant increases in the cost of care for these patients. Nearly $70 \%$ of patients in the current study were dependent on over three activities of daily living prior to hip fracture, yet all but one were ambulatory using walking aids (cane/walker). Remarkably, $46 \%$ of patients lived in their home, with the remaining residing in some form of assisted living. Forster et al reported that only six (46\%) patients to be ambulatory prior to surgery [8] and Oliver et al. observed that $55.6 \%$ of their subjects were ambulatory with the help of walking aids [9]. In both studies less than $50 \%$ of the patients returned to their preoperative residential status and only $11 \%$ returned to their home (Table 2). In the current study, all but two surviving patients returned to the preoperative ambulatory status. Two patients remained bed or wheel chair bound due to decubitus ulcer. As expected no patient returned directly to home following surgery. Considering the significant costs associated with the provision of long term care these results raise concerns regarding the overall economic burden of acute and chronic health care following hip surgery in centenarians.

In an effort to reduce the cost of acute care hospitalization following the surgical treatment of hip fracture early transfer to nursing homes or rehabilitation centers is now the norm [17]. In 2008, nearly $70 \%$ of individuals $>85$ years old were discharged to a nursing home or rehabilitation center following surgery for hip fracture compared to $64 \%$ in 1998 . [18] Leibson et al reported that $57.4 \%$ of individuals who resided in the community prior to hip fracture were admitted to nursing home within three months following surgery and spent on an average 161 days in residence during the following calendar year. Among those, 50\% were eventually discharged to home, $25 \%$ became permanent nursing home residents and 25\% died within 12 months [19]. This trend has shifted costs from acute care hospitals to long term care facilities, although the overall cost for hip fracture treatment may have remained unaffected. Based on cur- 
Table 2. Published reports on the clinical outcomes of hip fracture surgery in centenarians.

\begin{tabular}{|c|c|c|c|c|c|c|c|c|c|c|c|}
\hline $\begin{array}{l}\text { Author, } \\
\text { Year }\end{array}$ & Study period & $\mathrm{N}$ & $\mathrm{M}: \mathrm{F}$ & $\begin{array}{c}\text { Mean } \\
\text { Age (Y) }\end{array}$ & $\begin{array}{l}\text { ASA } \\
\text { grade }\end{array}$ & $\begin{array}{c}\text { Pre-operative } \\
\text { residential } \\
\text { status, } \mathrm{N}=(\%)\end{array}$ & $\begin{array}{c}\text { Pre-operative } \\
\text { ambulatory } \\
\text { status, } \\
\mathrm{N}=(\%)\end{array}$ & $\begin{array}{l}\text { Post-operative } \\
\text { residential } \\
\text { status, } \mathrm{N}=(\%)\end{array}$ & $\begin{array}{c}\text { Post-operative } \\
\text { ambulatory } \\
\text { status, } \\
\mathrm{N}=(\%)\end{array}$ & $\begin{array}{l}\text { Mortality, } \\
\mathrm{N}=(\%)\end{array}$ & $\begin{array}{l}\text { LOS, days } \\
\text { (range) }\end{array}$ \\
\hline $\begin{array}{l}\text { Forster } \\
\text { et al., } 2000^{7}\end{array}$ & 1988-1999 & 13 & $2: 11$ & 101 & NR & $\begin{array}{c}\text { H-5 (38) } \\
\text { RH-4 (31) } \\
\text { NH-3 (23) } \\
\text { HP-1 (8) }\end{array}$ & $\begin{array}{l}\text { I-2 (15) } \\
\text { A-2 (15) }\end{array}$ & $\begin{array}{l}\text { NH-2 (15) } \\
\text { HP-1 (8) } \\
\text { R-5 (38) }\end{array}$ & NR & 4, (31) & $13(2-26)$ \\
\hline $\begin{array}{l}\text { Oliver et al., } \\
\qquad 2004^{8}\end{array}$ & $1998-2002$ & 18 & $1: 17$ & 101.8 & $\begin{array}{c}\text { III/IV-5 } \\
0 \%\end{array}$ & H/RH-7 (39) & NR & $\begin{array}{c}\text { H-11.1\% } \\
\text { RH-11.1\% } \\
\text { NH-44.4\% } \\
\text { HP-11.1\% } \\
\text { R-11.1\% }\end{array}$ & $\begin{array}{c}\text { A-55.6\% } \\
\text { W/B-44.4\% }\end{array}$ & 2, (11.1) & 53.9 \\
\hline $\begin{array}{l}\text { Verma } \\
\text { et al., } 2009^{13}\end{array}$ & $2000-2007$ & 26 & $3: 23$ & 102 & $\begin{array}{c}\text { III/IV- } \\
12 \%\end{array}$ & $\begin{array}{c}\text { H-6 (26.1) } \\
\text { RH-7 (30.4) } \\
\text { NH-10 (43.5) }\end{array}$ & $\begin{array}{l}\text { Mean-Gr. } 4^{\mathrm{I}} \\
\text { Median-Gr. } 1^{\mathrm{II}}\end{array}$ & NR & NR & (17.3\%) & 20.7 \\
\hline $\begin{array}{l}\text { Current } \\
\text { series }^{\text {III }}\end{array}$ & 2000-2009 & 13 & $2: 11$ & 101.2 & $\begin{array}{l}\text { III/IV- } \\
75 \%\end{array}$ & $\begin{array}{c}\text { H-6 (50) } \\
\text { RH-3 (25) } \\
\text { NH-2 (16.7) } \\
\text { R-2 (16.7) }\end{array}$ & $\begin{array}{l}\text { A-8 (66.7) } \\
\text { As-3 (25) } \\
\text { U-1 (8.3) }\end{array}$ & $\begin{array}{l}\text { NH-6 (50) } \\
\text { R-5 (41.7) }\end{array}$ & $\begin{array}{c}\text { A-7 (58.3) } \\
\text { As-2 (16.7) } \\
\text { W/B-2 (16.7) } \\
\text { U-1 (7.7) }\end{array}$ & $1,(8.3)$ & $13(7-28)$ \\
\hline
\end{tabular}

Abbreviations: N: number of patients, M: male, F: female, Y: years, ASA: American society of anesthesiologist, NR: not recorded, H: home, RH: residential home, NH: nursing home, HP: hospital, I: independent, A: aids (cane, walker) R: rehabilitation, As: assistance, U: unknown, W/B: wheel chair/bed bound, ${ }^{\mathrm{I}} \mathrm{Gr}$. 4 = patients walk indoors only if accompanied, ${ }^{\text {II }} \mathrm{Gr} .1$ = patients could walk alone outdoors, ${ }^{\text {III }}$ calculations are done for patients who had surgery ( $\mathrm{N}=12$ ).

rent Medicare nursing home reimbursement charges (average $=\$ 399.19$ per diem) [20], affected individuals will spend an additional $\$ 61,180$ in nursing home costs in the year following hip fracture, exclusive of direct medical care cost like physical therapy and office visits. Melton et al. [21] have shown that the median cost of direct medical care (exclusive of nursing home expenditures) for hip fracture patients in the succeeding 12-month period was $\$ 13,354$, which is comparable to national estimates of $\$ 18,018$ - $\$ 23,120$ [22]. Braithwait et al. have estimated that the lifetime attributable cost of hip fracture was $\$ 81,300$, of which $\$ 8900$ was related to the initial hospi- talization, $\$ 3900$ to subsequent hospitalizations, $\$ 2300$ to rehabilitation facilities, $\$ 35,400$ to nursing facilities, and $\$ 30,800$ to home care, of which $\$ 24,600$ was informal unreimbursed care delivered by friends or family). Of the total costs, 33\% occurred in the first six months, $11 \%$ in the second six months, and 56\% after the first year [23]. In the US the aggregate charges ("the national bill”) for treating 100,000 patients >85 years of age with hip replacement, has increased from \$3,852, 389,571 to $\$ 5,226,661,873$ between 2004 and 2008, respectively, a $26.2 \%$ increase in cost of care [24]. While these costs are high, several studies have shown that surgery for hip fracture in the elderly yields a better return on money spent and quality of life compared to other life saving measures such as coronary artery bypass grafting and hemodialysis, however these findings cannot be generalized to all age groups [22]. A comprehensive cost/ benefit analysis for hip fracture surgery in centenarians is beyond the scope of this review, but what can be inferred from the published results is that expenditures towards hospitalization and surgical treatment following hip fracture represented only a small percent of the total health care burden.

\section{Conclusion}

Centenarians represent a high-risk-surgical group due to their age and associated comorbidities. Hip fracture is the cause for $>10 \%$ of all hospital admissions and over $29 \%$ of all surgical procedures in this age group. While the acute surgical admission for hip fracture is generally well tolerated, the trend towards early transfer to long term care facilities has resulted in a shift in the health care costs and an increased health care economic burden. Additional research is needed to provide a more complete cost benefit analysis and quality of life assessment of hip fracture surgery in centenarians, particularly in light of the increased number of patients expected to reach this advanced age in the future.

\section{REFERENCES}

[1] C. A. Krach, A. Victoria and U. S. Velkoff, "Bureau of the Census, Current Population Reports, Series P23199RV Centenarians in the United States,” US Government Printing Office, Washington, 1999.

[2] S. R. Cummings, S. M. Rubin and D. Black, “The Future 
of Hip Fractures in the United States. Numbers, Costs, and Potential Effects of Postmenopausal Estrogen," Clinical Orthopaedics and Related Research, Vol. 252, 1990, pp. 163-166.

[3] J. C. Scott, “Osteoporosis and Hip Fractures,” Rheumatic Disease Clinics of North America, Vol. 16, No. 3, 1990, pp. 717-740.

[4] S. E. Hall, J. A. Williams, J. A. Senior, P. R. Goldswain and R. A. Criddle, "Hip Fracture Outcomes: Quality of Life and Functional Status in Older Adults Living in the Community," Australian and New Zealand Journal of Medicine, Vol. 30, No. 3, 2000, pp. 327-332. doi:10.1111/j.1445-5994.2000.tb00833.x

[5] J. A. Grisso, J. L. Kelsey, B. L. Strom, et al., "Risk Factors for Falls as a Cause of Hip Fracture in Women. The Northeast Hip Fracture Study Group,” The New England Journal of Medicine, Vol. 324, No. 19, 1991, pp. 13261331. doi:10.1056/NEJM199105093241905

[6] J. M. Hausdorff, D. A. Rios and H. K. Edelberg, "Gait Variability and Fall Risk in Community-Living Older Adults: A 1-Year Prospective Study," Archives of Physical Medicine and Rehabilitation, Vol. 82, No. 8, 2001, pp. 1050-1056. doi:10.1053/apmr.2001.24893

[7] M. C. Hornbrook, V. J. Stevens, D. J. Wingfield, J. F. Hollis, M. R. Greenlick and M. G. Ory, "Preventing Falls among Community-Dwelling Older Persons: Results from a Randomized Trial,” Gerontologist, Vol. 34, No. 1, 1994, pp. 16-23. doi:10.1093/geront/34.1.16

[8] M. C. Forster and D. Calthorpe, "Mortality Following Surgery for Proximal Femoral Fractures in Centenarians," Injury, Vol. 31, No. 7, 2000, pp. 537-539. doi:10.1016/S0020-1383(00)00049-8

[9] C. W. Oliver and C. Burke, "Hip Fractures in Centenarians,” Injury, Vol. 35, No. 10, 2004, pp. 1025-1030. doi:10.1016/j.injury.2003.10.004

[10] R. Verma, A. S. Rigby, C. J. Shaw and A. Mohsen, "Acute Care of Hip Fractures in Centenarians-Do We Need More Resources?” Injury, Vol. 40, No. 4, 2009, pp. 368370. doi:10.1016/j.injury.2008.09.008

[11] G. Holt, D. Macdonald, M. Fraser and A. T. Reece, “Outcome after Surgery for Fracture of the Hip in Patients Aged over 95 Years,” Journal of Bone \& Joint Surgery, Vol. 88, No. 8, 2006, pp. 1060-1064. doi:10.1302/0301-620X.88B8.17398

[12] C. Ossendorf, M. J. Scheyerer, G. A. Wanner, H. P. Simmen and C. M. Werner, "Treatment of Femoral Neck Fractures in Elderly Patients over 60 Years of Age-Which Is the Ideal Modality of Primary Joint Replacement?” Patient Safety in Surgery, Vol. 4, No. 1, 2010, p. 16. doi:10.1186/1754-9493-4-16

[13] R. Hornby, J. G. Evans and V. Vardon, “Operative or Conservative Treatment for Trochanteric Fractures of the
Femur. A Randomised Epidemiological Trial in Elderly Patients," Journal of Bone \& Joint Surgery, British Volume, Vol. 71, No. 4, 1989, pp. 619-623.

[14] E. Krishnan, J. F. Fries and C. K. Kwoh, "Primary Knee and Hip Arthroplasty among Nonagenarians and Centenarians in the United States," Arthritis \& Rheumatism, Vol. 57, No. 6, 2007, pp. 1038-1042. doi:10.1002/art.22888

[15] M. P. van de Kerkhove, P. S. Antheunis, J. S. Luitse and J. C. Goslings, "Hip Fractures in Nonagenarians: Perioperative Mortality and Survival,” Injury, Vol. 39, No. 2, 2008, pp. 244-248. doi:10.1016/j.injury.2007.07.009

[16] J. E. Kenzora, R. E. McCarthy, J. D. Lowell and C. B. Sledge, "Hip Fracture Mortality. Relation to Age, Treatment, Preoperative Illness, Time of Surgery, and Complications," Clinical Orthopaedics and Related Research, Vol. 186, 1984, pp. 45-56.

[17] P. Haentjens, P. Autier, M. Barette and S. Boonen, "The Economic Cost of Hip Fractures among Elderly Women. A One-Year, Prospective, Observational Cohort Study with Matched-Pair Analysis. Belgian Hip Fracture Study Group,” The Journal of Bone \& Joint Surgery, Vol. 83, No. 4, 2001, pp. 493-500.

[18] Health Care Utilization Project Data on Outcome of Hip Fractures for the year 2008.

[19] C. L. Leibson, A. N. Tosteson, S. E. Gabriel, J. E. Ransom and L. J. Melton, "Mortality, Disability, and Nursing Home Use for Persons with and without Hip Fracture: A Population-Based Study,” Journal of the American Geriatrics Society, Vol. 50, No. 10, 2002, pp. 1644-1650. doi:10.1046/j.1532-5415.2002.50455.x

[20] The State Long-Term Health Care Sector. Characteristics, Utilization, and Government Funding: 2009 Update.

[21] L. J. Melton III, S. E. Gabriel, C. S. Crowson, A. N. Tosteson, O. Johnell and J. A. Kanis, "Cost-Equivalence of Different Osteoporotic Fractures,” Osteoporosis International, Vol. 14, No. 5, 2003, pp. 383-388. doi:10.1007/s00198-003-1385-4

[22] P. Haentjens, G. Lamraski and S. Boonen, "Costs and Consequences of Hip Fracture Occurrence in Old Age: An Economic Perspective,” Disability and Rehabilitation, Vol. 27, No. 18-19, 2005, pp. 1129-1141. doi:10.1080/09638280500055529

[23] R. S. Braithwaite, N. F. Col and J. B. Wong, "Estimating Hip Fracture Morbidity, Mortality and Costs," Journal of the American Geriatrics Society, Vol. 51, No. 3, 2003, pp. 364-370.

[24] HCUPnet, Healthcare Cost and Utilization Project (HCUP), "2004-2008 Agency for Healthcare Research and Quality,” Rockville, 2010. doi:10.1046/j.1532-5415.2003.51110.x 